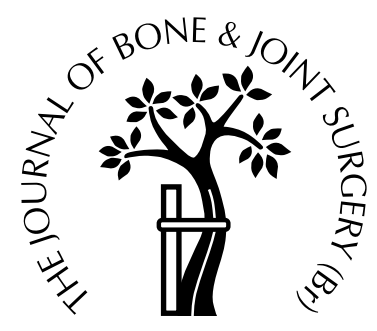

\title{
Total hip arthroplasty using porous-coated femoral components in patients with rheumatoid arthritis
}

\author{
A. K. Jana, C. A. Engh Jr, P. J. Lewandowski, R. H. Hopper Jr, \\ C. A. Engh \\ From the Anderson Orthopaedic Research Institute, Alexandria, USA
}

W e studied the results of total hip arthroplasty (THA) using AML porous-coated femoral components at a mean follow-up of 11 years in a non-selected, consecutive series of patients with rheumatoid arthritis. We reviewed 64 patients with 82 primary THAs using these components. There were seven men (8 hips) and 57 women (74 hips) with a mean age of 55.1 years $(24$ to 80$)$ at the time of surgery.

Nine patients (11 hips) died before the two-year follow-up. Of the remaining 71 hips, only one stem was revised for aseptic loosening. Survivorship for the stems was $98.1 \%$ (95\% confidence interval (CI) 94.5 to 100.0 ) at ten years, using a life-table analysis, with revision for any reason as an endpoint. Of the $\mathbf{7 0}$ unrevised stems, $66(94 \%)$ had bony ingrowth, while four $(6 \%)$ were radiologically loose at the most recent follow-up (mean 11.4 years). Our study shows the excellent long-term results which can be achieved with porous-coated femoral components in patients with rheumatoid arthritis.

J Bone Joint Surg [Br] 2001;83-B:686-90.

Received 20 July 2000; Accepted after revision 13 December 2000

Rheumatoid arthritis is a systemic inflammatory disease with multiple joint involvement. Its onset ranges from early childhood to late adulthood, with a marked variation in severity and clinical course. Despite numerous medical advances in its treatment, severe involvement of the hips is common. ${ }^{1}$ Fortunately, total joint arthroplasty can give reliable relief from pain and functional improvement.

A. K. Jana, MD, Staff Orthopaedic Surgeon

Woodbridge Orthopaedic Spine Centre, P.C. 3550 Lutheran Parkway West, Suite 201, Wheatridge, Colorado 80033 USA.

C. A. Engh Jr, MD, Orthopaedic Surgeon

R. H. Hopper Jr, PhD, Research Associate

C. A. Engh, MD, Medical Director

Anderson Orthopaedic Research Institute, PO Box 7088, Alexandria, Virginia, USA.

P. J. Lewandowski, MD, Staff Orthopaedic Surgeon

Crystal Clinic Inc, 3975 Embassy Parkway, Akron, Ohio, USA.

Correspondence should be sent to Dr C. A. Engh Jr.

(C)2001 British Editorial Society of Bone and Joint Surgery 0301-620X/01/511539\$2.00
Although porous-coated femoral and acetabular components have been used in the treatment of osteoarthritis for more than two decades, they have not been widely adopted for the treatment of rheumatoid arthritis. Orthopaedic surgeons have been concerned that the osteopenia, contractures, and bony deformities often found in patients with rheumatoid arthritis would make it difficult to obtain safely and reliably the initial stability of the prosthesis necessary for bony ingrowth. Also, there have been concerns relating to the obtaining and maintaining of bony ingrowth in the presence of systemic inflammatory disease.

We now assess retrospectively whether an uncemented femoral component is a viable option for patients with rheumatoid arthritis. We reviewed the long-term clinical and radiological results of a non-selected, consecutive series of patients with rheumatoid arthritis in which the porous-coated Anatomic Medullary Locking (AML) femoral component (DePuy; Johnson \& Johnson, Warsaw, Indiana) was used, in combination with one of three different acetabular designs.

\section{Patients and Methods}

A total of 82 consecutive, unselected primary total hip arthroplasties (THAs) using an AML stem was performed between November 1977 and December 1986 on 64 patients with either juvenile or adult-onset rheumatoid arthritis. There were seven men (eight hips) and 57 women (74 hips) with a mean age of 55.1 years (24 to 80) at the time of surgery, and a mean preoperative weight of $61 \mathrm{~kg}$ (34 to 136). Before operation 36 patients ( 44 hips) had been taking oral corticosteroids or at least one slow-acting antirheumatic drug, such as Plaquenil, methotrexate, or parenteral gold. In 35 patients (45 hips) the disease affected the joints in both the upper and the lower limbs, and in the other 29 (37 hips) only the lower limbs were primarily affected.

The AML component, designed to achieve biological fixation by bony ingrowth, has a straight stem with distally non-tapered, cylindrical geometry. In this study the extent of porous coating on the AML stems varied: 65 had extensive porous coating and 17 had proximal porous coating. The extensively porous-coated stems had more than $50 \%$ of their stems coated to allow for diaphyseal 
bony ingrowth, and the proximally-coated stems had onethird of their proximal end coated, with the goal of obtaining metaphyseal bony ingrowth. All femoral components were made of cobalt-chromium alloy with sintered cobaltchromium beads, providing a mean pore size of $250 \mu \mathrm{m}$. The technique used for the preparation and insertion of the femoral component has been described previously. ${ }^{2}$

Several different acetabular components were used according to their availability and the surgeons' preferences. A total of 23 cemented polyethylene cups was implanted between 1977 and 1983, 20 threaded cups with no porous coating between 1983 and 1985, and 39 porouscoated cups between 1982 and 1986. Screws were used in the peripheral rim in nine porous-coated cups, and three porous-coated spikes provided supplementary fixation on the other 30 porous-coated cups.

The level of pain and walking ability, based on the scale of Merle D'Aubigné and Postel, ${ }^{3}$ were recorded for each patient before operation and at each follow-up visit. Serial radiographs were assessed to determine the stability of the implant. The femoral component was classified as 'bone ingrown', 'stable with fibrous tissue ingrowth', or 'loose'. If serial radiographs showed subsidence of greater than $2 \mathrm{~mm}$, or greater than $5^{\circ}$ of varus or valgus tilt, the component was considered unstable. If there were no signs of bony ingrowth but no migration had occurred, we considered the component to be stably fixed by fibrous tissue. We also reviewed the immediate postoperative radiograph to determine whether the femoral component was appropriately sized relative to the femoral anatomy. ${ }^{2}$ All radiography was performed using the standard technique employed in our institution.

We also assessed the stability of the acetabular components. Signs of instability included tilting of greater than $5^{\circ}$, or migration of more than $2 \mathrm{~mm}$. Porous-coated cups which had a circumferential radiolucent line and bead shedding were considered to be loose, ${ }^{5}$ as were cemented and threaded cups with a continuous radiolucent line between the cement-bone interface or the bone-prosthesis interface. ${ }^{6,7}$ The presence of expansile osteolytic lesions was recorded in the zones described by Gruen, McNeice and Amstutz ${ }^{8}$ for the femur and by DeLee and Charnley ${ }^{9}$ for the acetabulum. We calculated the area of the osteolytic lesion by multiplying the maximum dimensions of the lesion in mutually perpendicular directions. All measurements were corrected for radiological magnification. Osteolytic lesions with an area greater than $1.5 \mathrm{~cm}^{2}$ were considered to be clinically significant.

Statistical analysis was undertaken using SPSS version 8.0 (SPSS, Chicago, Illinois). For all tests, a p value of less than or equal to 0.05 was considered to be statistically significant. Component survival was calculated using lifetable survivorship analysis. All survivorship estimates are reported with $95 \%$ confidence intervals.

\section{Results}

Lost to follow-up. Nine patients (11 hips), all now deceased, had a follow-up of less than two years. Considered as lost to follow-up, these patients were excluded from the evaluations of the clinical and radiological outcome but were included in the survivorship analyses. Of these hips, one threaded cup became unstable in the immediate postoperative period and was revised to a bipolar head five days after the primary procedure. None of the remaining ten hips was known to have been revised before the patient's death.

Reoperations among patients with a minimum followup of two years (15 hips). A total of 14 patients with a minimum follow-up of two years had 15 reoperations during the study period. These included one complete revision and 14 acetabular revisions (Table I). One patient

Table I. Reoperation summary in hips with a minimum follow-up of two years

\begin{tabular}{lll}
\hline $\begin{array}{l}\text { After operation } \\
\text { (yrs) }\end{array}$ & $\begin{array}{l}\text { Components } \\
\text { revised }\end{array}$ & $\begin{array}{l}\text { Revision } \\
\text { diagnosis }\end{array}$ \\
\hline 1.0 & Cemented cup & Recurrent dislocation \\
3.5 & Threaded cup & Loosening \\
5.7 & Threaded cup & Loosening \\
6.2 & Threaded cup & Loosening \\
7.7 & Cemented cup & Loosening \\
7.8 & Porous-coated cup & Loosening secondary to fracture/trauma \\
8.2 & Cemented cup & Loosening \\
8.2 & Threaded cup & Loosening \\
8.3 & Threaded cup & Loosening \\
9.2 & Porous-coated cup & Loosening \\
11.1 & Threaded cup & Loosening \\
11.4 & Cemented cup and AML stem & Loosening \\
12.8 & Cemented cup & Loosening \\
17.1 & Cemented cup & Loosening \\
18.4 & Cemented cup & Loosening \\
\hline
\end{tabular}


Table II. Life table for AML stems using revision for any reason as an endpoint

\begin{tabular}{|c|c|c|c|c|c|c|}
\hline \multirow[b]{2}{*}{$\begin{array}{l}\text { Years after } \\
\text { operation }\end{array}$} & \multirow[b]{2}{*}{$\begin{array}{l}\text { Number of } \\
\text { stems at } \\
\text { start }\end{array}$} & \multicolumn{2}{|c|}{$\begin{array}{l}\text { Number of stems } \\
\text { withdrawn }\end{array}$} & \multirow[b]{2}{*}{$\begin{array}{l}\text { Number of } \\
\text { stem } \\
\text { revisions }\end{array}$} & \multirow{2}{*}{$\begin{array}{l}\text { Cumulative } \\
\text { estimate of } \\
\text { survival } \\
(\%)\end{array}$} & \multirow[b]{2}{*}{$95 \% \mathrm{CI}$} \\
\hline & & $\begin{array}{l}\text { Died } \\
\text { without } \\
\text { revision }\end{array}$ & $\begin{array}{l}\text { Unrevised } \\
\text { at last } \\
\text { follow-up }\end{array}$ & & & \\
\hline 0 to $<2$ & 82 & 1 & 2 & 0 & 100.0 & 100.0 to 100.0 \\
\hline 2 to $<4$ & 79 & 5 & 0 & 0 & 100.0 & 100.0 to 100.0 \\
\hline 4 to $<6$ & 74 & 4 & 0 & 0 & 100.0 & 100.0 to 100.0 \\
\hline 6 to $<8$ & 70 & 3 & 1 & 0 & 100.0 & 100.0 to 100.0 \\
\hline 8 to $<10$ & 66 & 2 & 3 & 0 & 100.0 & 100.0 to 100.0 \\
\hline 10 to $<12$ & 61 & 5 & 9 & 1 & 98.1 & 94.5 to 100.0 \\
\hline 12 to $<14$ & 46 & 6 & 13 & 0 & 98.1 & 94.5 to 100.0 \\
\hline 14 to $<16$ & 27 & 2 & 13 & 0 & 98.1 & 94.5 to 100.0 \\
\hline 16 to $<18$ & 12 & 0 & 4 & 0 & 98.1 & 94.5 to 100.0 \\
\hline 18 to $<20$ & 8 & 1 & 5 & 0 & 98.1 & 94.5 to 100.0 \\
\hline 20 to $<22$ & 2 & 0 & 2 & 0 & 98.1 & 94.5 to 100.0 \\
\hline
\end{tabular}

with bilateral hip replacements had both cemented cups revised. Using revision of the femoral component for any reason as an endpoint, the survivorship of stems at ten years was $98.1 \%$ (95\% confidence interval (CI) 94.5 to 100.0) (Table II). The survivorship of acetabular components for revision due to aseptic loosening at ten years was 93.8\% (95\% CI 85.5 to 100.0) for porous-coated cups, $84.3 \%$ (95\% CI 68.0 to 100.0) for cemented cups and $54.1 \%$ (95\% CI 27.9 to 80.3 ) for threaded cups.

One patient, who was 59 years old at the time of primary arthroplasty, had a complete revision for loosening after 11.4 years. Her primary components were an extensivelycoated AML stem and a cemented, polyethylene acetabular component. Although serial radiographs had revealed an undersized stem that was not osseo-integrated, her symptoms had not been severe enough to require reoperation until the acetabular component became loose. The components were revised to a fully porous-coated femoral component and a hemispheric porous-coated acetabular component. At the last follow-up (5.2 years after revision) both components were radiographically stable.

One patient, who was 25 years old at the time of primary surgery, required acetabular revision for recurrent posterior dislocation one year after the initial procedure. The cemented cup was replaced with a porous-coated cup. The porous-coated femoral stem had osseo-integrated and was left in place. Subsequent to the revision, there were no further dislocations. At follow-up at 17 years (16 years after the revision), the components remained stably fixed.

The remaining 13 revisions were for aseptic loosening of the acetabular component. The types of cup which were revised were six threaded, five cemented and two porouscoated. One cemented cup was revised to an oblong porous-coated component. The other 12 cups (six threaded, four cemented and two porous-coated) were revised to porous-coated hemispherical cups.
The mean time to revision was 9.6 years (3.5 to 18.4) for all acetabular revisions. The mean time to revision was 7.2 years (3.5 to 11.1) for threaded cups, 12.8 years ( 7.7 to 18.4) for cemented cups and 8.5 years (7.8 to 9.2) for porous-coated cups.

The 14 hips which required isolated revision of the cup had radiographically bone-ingrown femoral components that were stable on examination during the operation. At follow-up at a mean of 13.4 years, these stems remained radiologically bone-ingrown. None of the femora had osteolytic lesions with areas greater than $1.5 \mathrm{~cm}^{2}$ on their last radiographic evaluation. Three had small lytic lesions $\left(0.10,0.20\right.$ and $\left.0.24 \mathrm{~cm}^{2}\right)$ in the calcar region (Gruen zone 7).

Unrevised cases (56 hips). Data on pain were available for 56 unrevised hips at a minimum of two years (mean 11.3 years). The pain component of the Merle D'Aubigné and Postel score ${ }^{3}$ improved from a mean of 2.6 preoperatively to a mean of 5.3 at the most recent follow-up. The pain score increased (indicating less pain) in 51 hips (91\%), remained the same in two hips (4\%), and decreased (indicating more pain) in three hips (5\%). The mean walking component of the score improved from 2.8 preoperatively to 4.3 at the most recent follow-up. The walking score improved in 34 hips $(61 \%)$, remained the same in 11 hips (20\%), and decreased in 11 hips (20\%).

In the 56 unrevised hips with a minimum radiological follow-up of two years (mean 10.9 years), four (7\%) of the femoral stems were loose and 52 (93\%) were boneingrown. Of the acetabular components, $49(88 \%)$ were stable and seven (12\%) were loose. Figure 1a shows an extensively porous-coated stem implanted with a porouscoated cup at six weeks after operation and Figure $1 \mathrm{~b}$ shows the same hip at follow-up at 12 years. Expansile femoral osteolytic lesions were identified in 15 (27\%) of the unrevised hips. The lesions were confined to Gruen 


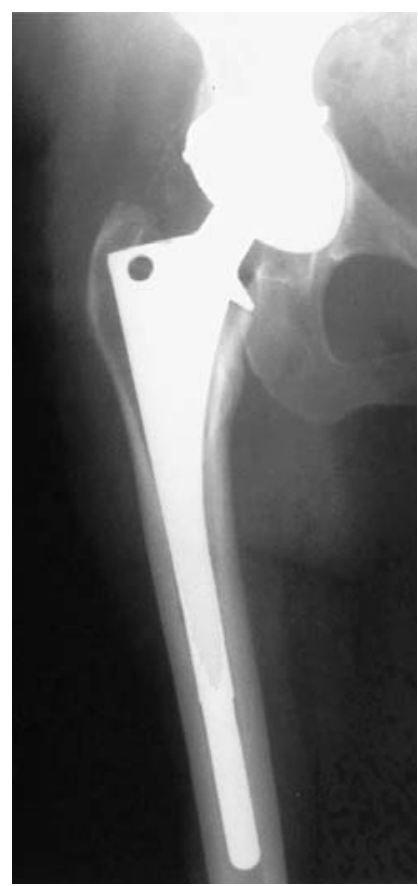

Fig. 1a

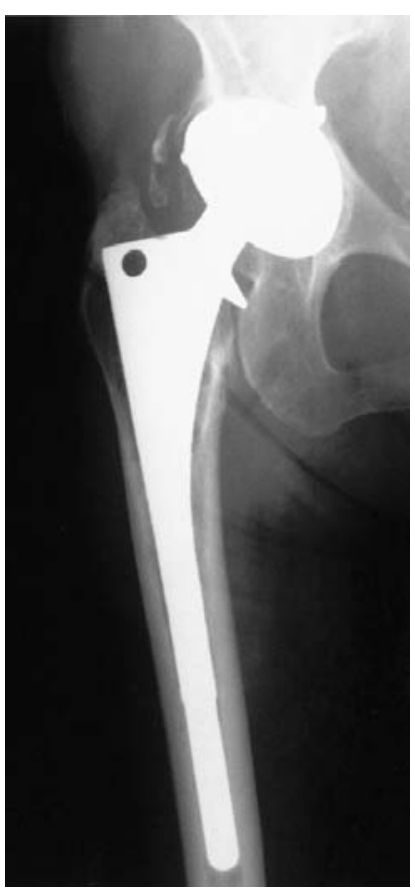

Fig. 1b

Anteroposterior radiographs of a 50-year-old woman who underwent THA for rheumatoid arthritis showing a) the radiological appearance of a canalfilling AML stem, extensively porous-coated and implanted with a porouscoated cup at six weeks after operation and b) a bone-ingrown stem and stable acetabular component at follow-up at 12 years. Mild calcar rounding has occurred, but there is no evidence of femoral or acetabular osteolysis.

zones 1 or 7 . Four femora had lesions which were larger than $1.5 \mathrm{~cm}^{2}$. Each of these large lesions was confined to Gruen zone 1, and one was associated with a pathological fracture of the greater trochanter. The mean radiological follow-up in hips with large femoral lesions was 15.8 years (13.0 to 18.8). Expansile acetabular osteolytic lesions were identified in eight $(14 \%)$ of the unrevised hips; five of these were larger than $1.5 \mathrm{~cm}^{2}$. The mean radiological follow-up in hips with large acetabular lesions was 15.4 years (12.5 to 19.3). Including both large and small lesions, the incidence of acetabular lysis was $16 \%(5 / 31)$ in porous-coated cups, $20 \%(3 / 15)$ in cemented cups, and $0 \%(0 / 10)$ in threaded cups.

Overall results (15 revised and 56 unrevised hips). In order to assess the incidence of femoral loosening, we reviewed the data for all stems with a minimum radiological follow-up of two years (mean 11.4). Of these 71 primary femoral components, 66 (93\%) were graded as bone-ingrown and five (7\%) were either radiologically loose at the last follow-up (four stems) or revised because of loosening (one stem). We found no difference between the rates of loosening of proximally and extensively-coated stems (Fisher's exact test, $\mathrm{p}=1.0$ ). Of the proximallycoated stems, 93\% (14/15) had bony ingrowth and 7\% (1/15) were radiologically loose at a mean follow-up of 10.4 years. Of the extensively-coated stems, 93\% (52/56) had bony ingrowth and $7 \%(4 / 56)$ were loose at a mean follow-up of 11.7 years.

We also assessed the incidence of loosening of the stem as related to filling of the femoral canal. Based on the immediate postoperative radiographs 49 (69\%) of the stems filled the femoral canal. At the most recent follow-up, 47 $(96 \%)$ were bone-ingrown and two (4\%) were loose; 22 $(31 \%)$ of the stems were undersized relative to the femoral canal, and of these, $19(86 \%)$ later became bone-ingrown and three $(14 \%)$ became loose. Despite a 3.3-fold increase in the relative risk, the rates of loosening between canalfilling and undersized stems were not significantly different (Fisher's exact test, $\mathrm{p}=0.17$ ).

Similarly to the femoral stems, we assessed loosening of the acetabular component. Our review included all cups with a minimum follow-up of two years in addition to the one cup revised for loosening at less than two years. Of these 72 acetabular components, 50 (69\%) were graded as stable, and $22(31 \%)$ were either radiologically loose at the last follow-up (seven hips) or revised for loosening (15 hips). Of the different types of acetabular component, $6 \%$ $(2 / 33)$ of the porous-coated cups were revised, 54\% (12/22) of the cemented cups were loose or revised, and $47 \%(8 / 17)$ of the threaded cups were loose or revised.

\section{Discussion}

The survival of porous-coated femoral stems in our series has been excellent. To date, there has been only one revision for aseptic loosening. The ten-year survivorship for stems using revision for loosening as an endpoint was $98.1 \%$ (95\% CI, 94.5 to 100.0 ). Four additional stems were radiologically loose at the most recent follow-up; when adding these stems to the one revised case, the incidence of loosening of the stem among all hips with a minimum radiological follow-up of two years was $7 \%(5 / 71)$ at a mean follow-up of 11.4 years.

To our knowledge, there have been no other long-term follow-up studies of the use of uncemented femoral components in patients with rheumatoid arthritis. However, the results which have been published with a mean follow-up of 4.5 to 5.5 years have been encouraging. In these smaller series, the reported rate of revision for cementless stems ranged from $0.0 \%$ to $2.9 \% .^{10-12}$ In the literature there are only two series of cemented THAs in patients with rheumatoid arthritis which are comparable to ours in terms of the length of follow-up and the number of patients. Creighton et $\mathrm{al}^{13}$ reported a femoral revision rate of $1 \%$ and a loosening rate of $2 \%$ in 106 consecutive, cemented THAs in patients with adult-onset rheumatoid arthritis followed for a mean of 12.1 years. After a similar follow-up period, Chmell et al $^{14}$ showed a rate of femoral revision of $18 \%$ with cemented THAs in rheumatoid patients who were less than 30 years old. Other series have reported revision and loosening rates between $2 \%$ and $18 \%$. $^{15-17}$

Durable acetabular fixation has been more difficult to 
attain than femoral fixation. In our patients the most common reason for reoperation was acetabular loosening. Although this could be partially attributed to the higher rate of revision occurring with the threaded acetabular components, the fact that three different types of cup were used and the length of follow-up for each of these types was different, makes analysis of the acetabular results difficult. It is more important to acknowledge that the acetabular loosening rate of $30 \%$ may have had an effect on the femoral loosening rate. If a patient has symptoms of a loose acetabular component causing limitation of activity, it is possible that the stresses applied to the femoral component will be substantially reduced. Among hips with a minimum follow-up of two years, however, there was an incidence of stem loosening of $14 \%(3 / 21)$ associated with cup loosening and of only $4 \%(2 / 50)$ with stable cups. In the 14 hips which underwent isolated cup revision, all femoral components were found to be well fixed, and none has subsequently loosened at a mean follow-up of 4.4 years $(0.1$ to 16.1) after the revision.

From our analysis of the variables influencing loosening of the stem, it appeared that the primary determinant of loosening was the extent of filling of the femoral canal by the prosthesis. Of the 49 stems judged to fill the femoral canal, only two (4\%) became loose. By contrast, of the 22 stems which were undersized relative to the femoral canal, three $(14 \%)$ became loose. Although undersized stems had a relative risk of loosening that was 3.3 times greater than the canal-filling stems, the difference in the rates of loosening among the groups was not statistically significant (Fisher's exact test, $\mathrm{p}=0.17)$. Patients who had canal-filling stems attained bony ingrowth at a rate of $96 \%$ which is similar to that attained in patients with diagnoses other than rheumatoid arthritis. ${ }^{5}$ In addition, no osseointegrated stem loosened during the period of our study. The percentage of proximally and extensively-coated AML stems which achieved stability by bony ingrowth was similar for both stems (93\%).

Although THA in patients with rheumatoid arthritis provides reliable relief from pain, the overall improvement in function is often limited by disease in other joints. ${ }^{12,16} \mathrm{At}$ the most recent follow-up, $91 \%$ of our patients had less pain after their THA and 5\% had more. However, only $61 \%$ of our patients had an improved Merle D'Aubigné and Postel walking score; $20 \%$ had lower scores. Increasing age, medical infirmity and multiple joint involvement often combine to limit walking ability in patients with rheumatoid arthritis.

We believe that this study demonstrates that reliable, durable femoral fixation can be achieved with a straight, cylindrical porous-coated stem in patients with rheumatoid arthritis. The surgeon should, however, ensure that the prosthesis fills the femoral canal so that intimate contact is obtained with the endosteal cortical bone surface.

No benefits in any form have been received or will be received from a commercial party related directly or indirectly to the subject of this article.

\section{References}

1. Lehtimäki MY, Kaarela K, Hämäläinen MM. Incidence of hip involvement and need for total hip replacement in rheumatoid arthritis: an eight-year follow-up study. Scand $J$ Rheumatol 1986;15:387-91.

2. Engh CA, Bobyn JD. Technique for primary surgery. In: Biological fixation in total hip arthroplasty. Thorofare, New Jersey, Slack Inc, 1985.

3. Merle d'Aubigné R, Postel M. Functional results of hip arthroplasty with acrylic prosthesis. J Bone Joint Surg [Am] 1954;36-A:451-75.

4. Engh CA, Massin P, Suthers KE. Roentgenographic assessment of the biologic fixation of porous-surfaced femoral components. Clin Orthop 1990;257:107-28.

5. Engh CA Jr, Culpepper WJ II, Engh CA. Long-term results of use of the anatomic medullary locking prosthesis in total hip arthroplasty. J Bone Joint Surg [Am] 1997;79-A:177-84.

6. Hodgkinson JP, Shelley P, Wroblewski BM. The correlation between the roentgenographic appearance and the operative findings at the bone-cement junction of the socket in Charnley low friction arthroplasties. Clin Orthop 1988;228:105-9.

7. Mulroy RD Jr, Harris WH. The effect of improved cementing techniques on component loosening in total hip replacement: an 11-year radiographic review. J Bone Joint Surg [Br] 1990;72-B:75760.

8. Gruen TA, McNeice GM, Amstutz HC. "Modes of failure" of cemented stem-type femoral components: a radiographic analysis of loosening. Clin Orthop 1979;141:17-27.

9. DeLee JG, Charnley J. Radiological demarcation of cemented sockets in total hip replacement. Clin Orthop 1976;121:20-32.

10. Haber D, Goodman SB. Total hip arthroplasty in juvenile chronic arthritis: a consecutive series. J Arthroplasty 1998;13:259-65.

11. Lachiewicz PF. Porous-coated total hip arthroplasty in rheumatoid arthritis. J Arthroplasty 1994;9:9-15.

12. Walker KR, Kyle RF, Gustilo RB. Noncemented femoral components in total hip arthroplasty for patients with rheumatoid arthritis. Minn Med 1996;79:27-31.

13. Creighton MG, Callaghan JJ, Olejniczak JP, Johnston RC. Total hip arthroplasty with cement in patients who have rheumatoid arthritis: a minimum ten-year follow-up study. J Bone Joint Surg [Am] 1998;80-A:1439-46.

14. Chmell MJ, Scott RD, Thomas WH, Sledge CB. Total hip arthroplasty with cement for juvenile rheumatoid arthritis: results at a minimum of ten years in patients less than thirty years old. $J$ Bone Joint Surg [Am] 1997;79-A:44-52.

15. Lehtimäki Y, Lehto MUK, Kautianen H, Savolainen HA, Hämäläinen MMJ. Survivorship of the Charnley total hip arthroplasty in juvenile chronic arthritis: a follow-up of 186 cases for 22 years. $J$ Bone Joint Surg [Br] 1997;79-B:792-5.

16. Severt R, Wood R, Cracchiolo A, Amstutz HC. Long-term followup of cemented total hip arthroplasty in rheumatoid arthritis. Clin Orthop 1991;265:137-45.

17. Unger AS, Inglis AE, Ranawat CS, Johanson NA. Total hip arthroplasty in rheumatoid arthritis: a long-term follow-up study. $J$ Arthroplasty 1987;2:191-7. 